\title{
Effects of Storage Conditions of Bovine Ovaries and Oocytes on the Success Rate of in Vitro Fertilization and Culture
}

\author{
Haruhiko NAKAO and Norio NAKATSUJI \\ Division of Developmental Biology, Meiji \\ Institute of Health Science, 540 Naruda, \\ Odawara 250, Japan
}

\begin{abstract}
The present study was carried out to examine effects of storage conditions of bovine ovaries and/or oocytes on the success rate of in vitro fertilization (IVF) and subsequent in vitro culture (IVC) of the zygotes. Ovaries obtained from a slaughter house were stored in Ringer solution at 39C (group 1), 20C (group 2), or 4C (group 3). In another group, immature oocytes were isolated from ovaries and stored in TCM-199 medium at 39C (group 4). The entire collection procedures of the ovaries took approximately $3 \mathrm{~h}$ at the slaughter house from the time of slaughter. The ovaries and/or the oocytes were stored under the conditions described above for $5 \mathrm{~h}$ before the experiment. In the control group, oocytes were isolated from the ovaries and cultured immediately to induce maturation. Following IVF and IVC, none of the zygotes developed to morula stage in group 1 and 3 . In group 2, some zygotes developed to morula or blastocyst stage $(11 \%, 7 \%$ respectively), but the rates were significantly lower than in the control group $(32 \%, 15 \%)$. Group 4 gave high success rates $(38 \%, 13 \%)$ similar to those attained in the control gorup.
\end{abstract}

Key words: Ovary storage, In vitro fertilization, Bovine oocytes.

(J. Reprod. Dev. 38: 11-13, 1992)

$\mathbf{T}$ o carry out in vitro fertilization (IVF) of bovine oocytes, the ideal situation would be to proceed IVF immediately after the collection of ovaries at a slaughter house. Practically, however, it usually takes a long time to collect ovaries and bring them from a remote slaughter house to a laboratory. This is particularly true in Japan where only a small number of slaughter houses cover large areas. The method for storing the ovaries for several hours is particularly useful.

By culturing 8-cell stage IVF embryos in rabbit oviducts, Shioya et al. [1] reported that storage of bovine ovaries at $38 \mathrm{C}$ for several hours reduced the rate of blastocysts formation. If oocytes were isolated from ovaries at a slaughter house within $40 \mathrm{~min}$ after slaughter, $28.6 \%$ of 8 -cell stage embryos developed to blastocysts, whereas only $14.3 \%$ of 8-cell stage embryos did so, if ovaries had

Accepted for Publication: June 26, 1991

Correspondence: H. Nakao been stored for $3 \mathrm{~h}$. The object of this paper is to find an optimal storage condition of bovine ovaries and oocytes for IVF and the subsequent culture of the zygotes in vitro (IVC).

\section{Materials and Methods}

\section{Storage of ovaries and immature oocytes}

Ovaries of adult cows and heifers were obtained from a slaughter house. They were divided into 5 experimental groups. In group 1-3, the ovaries were stored in Ringer solution (RS) at different temperatures of 39C (group 1), 20C (group 2), or $4 \mathrm{C}$ (group 3). In group 4, the ovaries were stored in RS at $39 \mathrm{C}$ during their collection, and then immature oocytes were sucked from the follicles having a diameter of $1-5 \mathrm{~mm}$ into a syringe with an 18G needle [2], stored in $10 \mathrm{ml}$ of TCM-199 medium supplemented with $25 \mathrm{mM}$ HEPES in a 
glass test tube kept at 39C. Group 5 was a control, where immature oocytes were isolated from the follicles immediately after the collection of the ovaries, and cultured to induce oocyte maturation.

Since it took about $3 \mathrm{~h}$ for the collection of the enough number of ovaries in the slaughter house, the average duration of the storage of the ovary is considered as $1.5 \mathrm{~h}$. The ovaries in group 1-3 and the oocytes in group 4 were kept for additional $5 \mathrm{~h}$ at the designated temperature in a thermos bottle.

\section{IVF and IVC}

The procedures of IVF and IVC are same as those described by Nakao and Nakatsuji [3]. Collected oocytes of all groups were cultured for $20 \mathrm{~h}$ in TCM-199 to complete the maturation process. The matured oocytes thus prepared were fertilized by the capacitated sperm following ionophore treatment [4]. Ova which retained their cumulus cells were cultured in plastic culture dishes (Falcon 3001) containing TCM-199 for 48 h. When the cumulus cells dissociated themselves, the embryos were transferred and cultured further on the monolayer culture of cumulus cells [5] in TCM-199 medium supplemented with $2 \%$ FCS at $39 \mathrm{C}$ under an atmosphere of $5 \% \mathrm{CO}_{2}, 5 \% \mathrm{O}_{2}$, and $90 \% \mathrm{~N}_{2}$.

\section{Results and Discussion}

Table 1 shows results of the experiment. We obtained no embryonic development beyond 8-cell stage in group 1 and 3.

The oocytes from the ovaries stored at 20C (group 2) developed to morula and blastocyst stages at significantly lower rate than in the control group. On the other hand, group 4 gave a similar rate of development to morula and/or blastocyst stage as the control group.

Shioya et al. [1] reported that storage of the isolated oocytes in TCM-199 at 39C immediately after the collection of the ovary improved the rate of the successful development to the blastocyst stage, in comparison with the ovaries stored in toto at a slaughter house. Thus the isolated oocytes can be stored for a longer period than those in toto.

In excised ovaries, lack of the blood circulation will produce deteriorating conditions for the oocytes, such as low oxygen tension and accumulation of toxic metabolites. Lowering the storage temperatures of the excised ovary or isolation of oocytes shortly after the slaughter will avoid these effects.

Yang et al. [6] investigated the cleavage rate of the bovine embryos derived from IVF of the oocytes obtained from the ovaries stored in PBS at $37 \mathrm{C}, 25 \mathrm{C}$, or $4 \mathrm{C}$, found a drastic decrease of the cleavage rate (from $69.4 \%$ to $8.0 \%$ ) when the ovaries had been stored for $8 \mathrm{~h}$ at $37 \mathrm{C}$, and concluded that the storage of ovaries at $25 \mathrm{C}$ was optimal in this regard. In our study for the development of embryos, the storage of ovaries at $20 \mathrm{C}$ gave results better than the storage at $39 \mathrm{C}$ or $4 \mathrm{C}$. The reason is unknown for why follicular oocytes stored in lower temperature (4C) gave worse result than those stored in higher temperature (20C).

Table 1. Development of bovine IVF embryos after storage of ovaries and/or oocytes under various conditions.

\begin{tabular}{|c|c|c|c|c|c|c|c|c|}
\hline & \multicolumn{4}{|c|}{ Condition of storage } & \multirow{2}{*}{$\begin{array}{l}\text { No. of } \\
\text { oocytes }\end{array}$} & \multicolumn{3}{|c|}{ No. of embryos (\%) } \\
\hline & stored as & temperature & time & medium & & 8-cell & morula $^{\text {a) }}$ & blastocyst ${ }^{\mathrm{b})}$ \\
\hline Group 1 & ovary & $39 \mathrm{C}$ & $6.5 \mathrm{~h}$ & $\mathrm{RS}^{\mathrm{c})}$ & 114 & $1^{\mathrm{c}}$ & 0 & 0 \\
\hline Group 2 & ovary & $20 \mathrm{C}$ & $6.5 \mathrm{~h}$ & RS & 172 & $34(20 \%)^{\mathrm{b}}$ & $19(11 \%)^{b}$ & $12(7 \%)^{\mathrm{b}}$ \\
\hline Group 3 & ovary & $4 \mathrm{C}$ & $6.5 \mathrm{~h}$ & RS & 153 & $5(3 \%)^{\mathrm{c}}$ & 0 & 0 \\
\hline \multirow[t]{2}{*}{ Group 4} & $\begin{array}{c}\text { ovary } \\
\downarrow\end{array}$ & $39 \mathrm{C}$ & $1.5 \mathrm{~h}$ & $\begin{array}{c}\mathrm{RS} \\
\downarrow\end{array}$ & $\begin{array}{c}138 \\
\downarrow\end{array}$ & & & \\
\hline & oocyte & $39 \mathrm{C}$ & $5.0 \mathrm{~h}$ & ТСМ-199 & 138 & $51(37 \%)^{a}$ & $38(28 \%)^{\mathrm{a}}$ & $18(13 \%)$ \\
\hline Group 5 & ovary & $39 \mathrm{C}$ & $1.5 \mathrm{~h}$ & RS & 94 & $46(49 \%)^{\mathrm{a}}$ & $30(32 \%)^{a}$ & $14(15 \%)^{\mathrm{a}}$ \\
\hline
\end{tabular}

a): Examined at $120 \mathrm{~h}$ after insemination.

b): Examined at $168 \mathrm{~h}$ after insemination.

c): Ringer solution.

Means with different superscripts are significantly different $(\mathrm{p}<0.05)$. 


\section{Acknowledgments}

The authors thank all the members of the staff at Ibaraki Chuo Shokuniku Kosha and Ken-hoku Meat Inspection Station for their help in obtaining the bovine ovaries. This work was carried out as a project of the E. T. Research Group supported in part by a grant from the Ministry of Agriculture, Forestry and Fishery, Japan.

\section{References}

1. Shioya Y, Kuwayama M, Ueda S, Saitou S, Oota $\mathbf{H}$, Hanada A. Effect of the time between slaughter and aspiration of follicles on the developmental capability of bovine oocytes matured and fertilized in vitro. Jpn J Anim Reprod 1988; 34: 39-43 (in Japanese).

2. Leibfried ML, First NL. Characterization of bovine follicular oocytes and their ability to mature in vitro. J Anim Sci 1979; 48: 76-86.

3. Nakao H, Nakatsuji N. Effects of co-culture, medium components and gas phase on in vitro culture of in vitro matured and in vitro fertilized bovine embryos. Theriogenology 1990; 33: 591-600.

4. Hanada A. In vitro fertilization of the cow. Jpn J Anim Reprod 1985; 31: 56-61 (in Japanese).

5. Goto K, Kajihara Y, Kosaka S, Koba M, Nakanishi Y, Ogawa K. Pregnancies after co-culture of cumulus cells with bovine embryos derived from in vitro fertilized in vitro matured follicular oocytes. J Reprod Fertil 1988; 83: 753-758.

6. Yang NS, Lu KH, Gordon I. In vitro fertilization (IVF) and culture (IVC) of bovine oocytes from stored ovaries. Theriogenology 1990;33: 352. 